\title{
A New Generation of Information Resource Directory System Based on Block Chain Technology
}

\author{
Hongzhuo Li, Shaofu Lin \\ Beijing University of Technology, Beijing, China
}

Keywords: Information resource management; Directory system; Block chain; Distributed system.

\begin{abstract}
This paper analyzes the overall structure and construction status of the current government information catalogue system, and points out the problems of data cross repetition in the actual application, and then designs the information resources of distributed management metadata through the combination of block chain technology and information resource catalog management technology. The directory system is a new generation of information resource directory architecture based on block chain technology, which has the characteristics of distributed maintenance, real-time update, power and responsibility traceability, and security and reliability.
\end{abstract}

\section{Introduction}

From 1995 to 1998, after the six Dublin core seminar, the Dublin core elements set up by 15 elements were formulated. Because of its simplicity and ease of use, it meets the needs of network development, and has been widely supported by various relevant standards. Now it has become the formal standard RFC2413 of Internet and the national information standard Z39.85 of the United States. At the same time, the Chinese Academy of Sciences and other institutions have set up the core metadata of the Chinese Core metadata standard scientific database, and the information resource catalogue system of China has been developing [1] vigorously. Since 2016, the State Council has promulgated the "administrative information resources sharing management line". The national development and Reform Commission has formulated a guide for the compilation of the government information resources catalogue, which clearly defines the classification of government information resources, the responsibility side, the format, the attributes, the renewal time limit, the sharing type, the sharing mode and the use requirements. It provides a specific method for the construction of government information resources directory system and the opening and sharing of government information resources [2-3].

\section{Research and Construction of Government Information Resources Directory System at Home and Abroad}

\section{1 general framework of Government Information Resources Catalogue System}

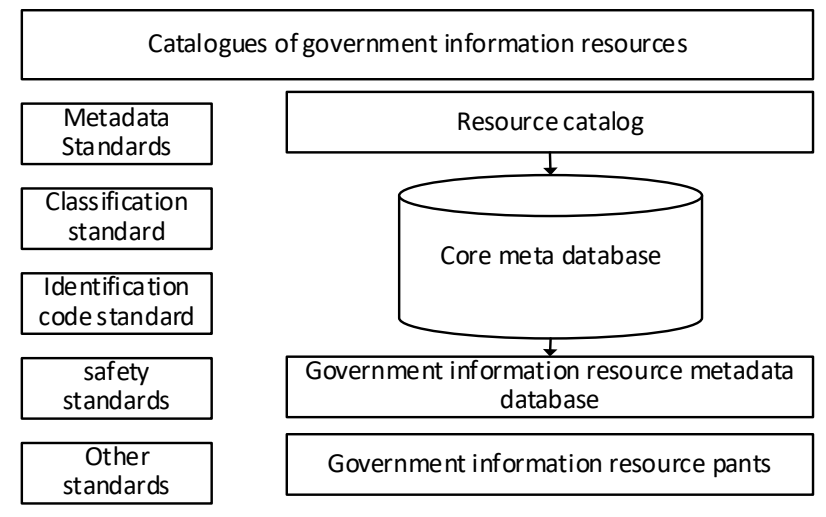

Figure 1 model of government information resource catalog system

A complete directory system model of government information resources is composed of 
information resources, metadata, directory of government information resources, standard specification and so on, as shown in Figure 1. [4]

\subsection{The technical framework of government information resource catalog system}

The technical structure of the directory system is mainly divided into the software and hardware environment and the network infrastructure, the data resource layer, the directory service function layer and the directory service presentation layer, as shown in Figure 2. [5]

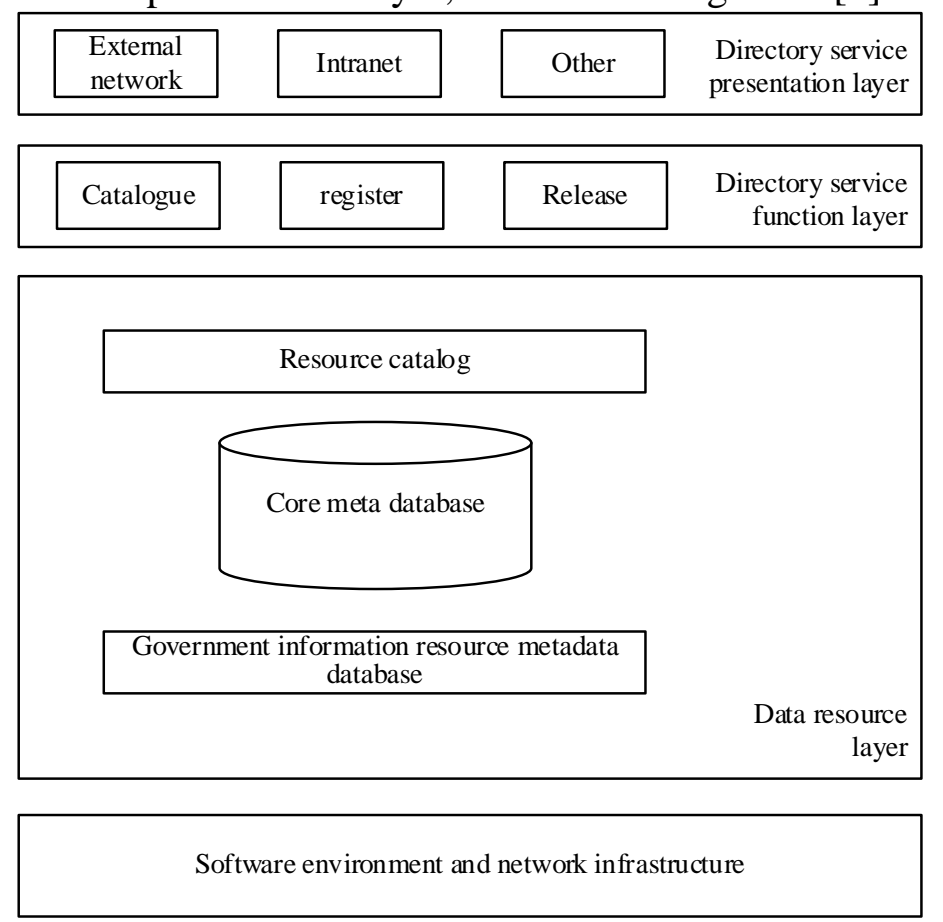

Figure 2 technical framework of Government Information Resources Catalogue System

\section{Research and analysis of government information resource catalog system}

\subsection{Information resource catalog management}

As the capital of Beijing, its information resource management system is very complex. It is one of the most typical examples of the application of information resources management system in China. At present, the information resource management center of Beijing is speeding up the exploration and research of the new generation of government information resources management system through various related topics. Therefore, the author takes the information resource catalog system in Beijing as a prototype.

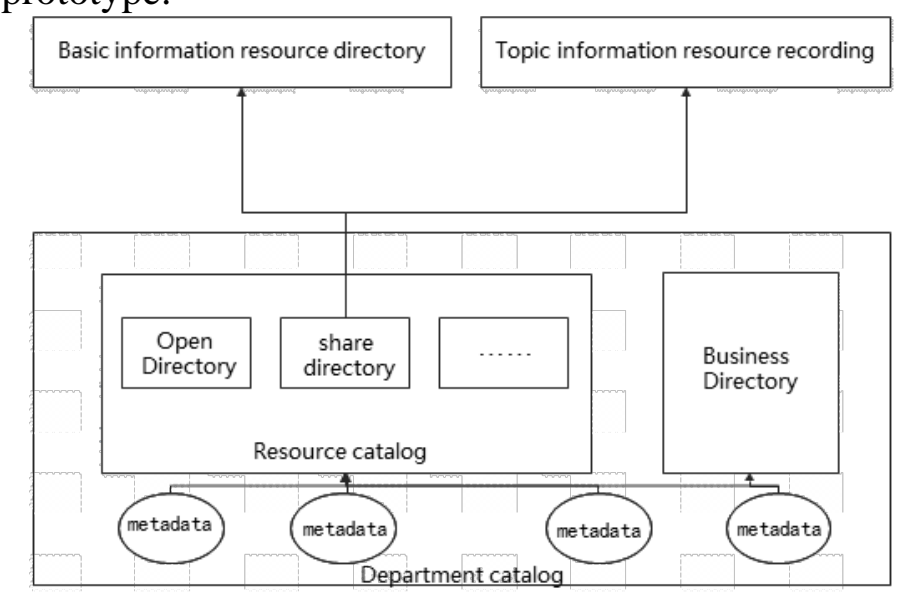

Figure 3 Government Information Resources Catalogue System

According to the resources attribute, the Information Resources Catalogue of Beijing is divided 
into three types, such as the basic information resource catalogue, the theme information resource catalogue, the Department information resource catalogue, and so on. The forms of various catalogues are as shown in Figure 3.

Departmental catalogues are compiled by departments (such as department business involving other departments to coordinate and share). The catalogue of shared open resources is finely divided according to the requirements of the construction of the catalogue of basic information resources and the information resources of government subject matter. The government basic information resource catalogue is similar to the generation method of the government subject resource directory, and is compiled on the basis of the shared catalogue of the relevant departments. The establishment, maintenance and renewal shall be held by the main responsibility department or the lead responsibility department.

\subsection{Department Information Resources Catalogue}

The definition Department catalogue is compiled by the Department (such as the Department business involves the coordination and sharing of other departments). The business catalogues and resource catalogues are formed according to the Department's business functions and the resources that are mastered, and the collection and combing of information resources within the Department is instructed. In addition to the Department, the Department information resource catalogue will subdivide the shared open resource catalogue in accordance with the requirements of the construction of the basic information resource catalogue and the government subject information resource catalogue, and provide support for its cataloging. At the same time, it provides index function for sharing and exchanging information resources. The maintenance and updating of departmental catalogues are jointly handled by departments and departments.

\subsection{Directory Department of basic information resources}

The directory of basic information resources and government subject information resources is an integrated directory, which is stored separately in a specially established basic directory library and subject catalogue library. In the process of compiling the Department catalogue, we need to select the metadata that needs to be shared and form an open catalogue of departments. On this basis, we will form two kinds of comprehensive catalogues. However, in the actual operation, in order to compile the comprehensive catalogue, it is often inferior to the establishment of the open directory of the Department. It is very difficult to organize the metadata and form a comprehensive catalogue.

\subsection{Problems in the current directory system}

At present, the information resource catalog management system in Beijing is a "physically dispersed and logically centralized" service system, which leads to the maintenance and renewal of the catalogues through the active maintenance of the responsible units.

The concept of current directory management is "line functions, business, information as the main line", the form of catalog generation is based on the Department catalog, and collate all kinds of comprehensive catalogues. However, due to the complexity of the Department's functions and business, its combing is very difficult, which greatly affects the sorting out of information and data resources. At the same time, the relationship from business to information to information, from information to data is complex, and there is a lot of cross, repetition and one to many, many to many relationships, making the relationship very complicated and work difficult to carry out.

Based on the various difficulties encountered by the current management mode based on the Department directory, I consider whether a more underlying and intuitive management method can be established to simplify the management of the Department catalogue. At this point, the emergence of block chaining technology provides the Internet with a way of solving problems without center and distribution. The metadata is stored in the block chain system, so that each metadata is like a bit currency, which can be developed and maintained by different users. The cross, repetition, one to many, and many to many problems will be solved in the Department based management model. 


\section{References}

[1] state department. National hair [2016] 51, 2016.9.5

[2] Zhang Naiding, Li Gang. Urban construction information resources directory system construction research [J]. science and technology information (science teaching and Research), 2008, (07): 29-31.

[3] Zhu Yuelong, Xu Feng, Feng Jun, Zhou Xiaofeng. Construction of water resources information resources directory system [J]. water conservancy informatization, 2010, (02): 4-8.

[4] Li Wensheng. Theory and practice of government information resources directory system [J]. library science research, 2011, (17): 10-15+37.

[5] Guo Jia Yi. Problems related to the directory system of government information resources [J]. e-government, 2005, (21): 70-76. 